Administrative Issues Journal: Connecting Education, Practice, and Research, Winter 2019

Vol. 9, No. 2: 12-27. DOI: 10.5929/9.2.2

\title{
Teacher Hiring: The disconnect between research based best practice and processes used by school principals
}

\author{
Laurie Kimbrel, Ed.D. \\ University of West Georgia
}

\begin{abstract}
Student success is dependent on teacher quality; therefore, it is imperative that principals hire the teachers most likely to experience success as measured by the impact on student outcomes. This study investigated teacher hiring processes to determine the extent to which practices that are supported by selection science and teacher quality research are utilized by school principals. Data were gathered using a survey e-mailed to principals in ten states in the southern and western regions of the United States. Analysis indicated that principals do not use consistent processes and vary the hiring approach based on their opinion of conditions. Principals favor traditional interviews as the primary teacher selection instrument and are unlikely to utilize predictive screening tools or research-based structured interviews. In most cases, principals do not make final hiring decisions based on measurable data or research-based qualities known to be predictive of high teacher performance. Most principals reported extremely limited teacher selection training through one-time workshops and graduate courses. This research is limited by the participation of principals in only ten states but implies that there is a disconnect between research-based best practices for teacher hiring and the actual processes used by principals.
\end{abstract}

Keywords: Teacher Hiring, Teacher Quality, Structured Interviews, Research Based Personnel Selection

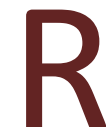

esearch over the last thirty years has provided evidence of an undeniable relationship between teacher quality and student outcomes (Ballard \& Bates, 2008; Darling-Hammond, 2000; Hattie, 2009; Marzano, 2003; Stronge, Ward, Tucker, \& Hindman, 2008). Receiving instruction from a highquality teacher has consistently been found to have a greater impact on students than a variety of other school and home level factors. In fact, teachers have two to three times the impact of any other school factor, including programming, school leader, and access to technology (Marzano, 2003; Teachers Matter, 2012). In this era of accountability for student achievement, school principals are under increasingly intense pressure to ensure and document that every student receives quality instruction and learns at high levels (Troutman, 2012). Given the documented connection of high-quality teachers to student achievement and the complexity of the roles of school leaders, it is imperative that only the teachers who have the greatest probability of success are hired, rather than those who will maintain the status quo or perform poorly.

Hiring effective teachers can be a challenging task that is made even more difficult by the fact that most principals do not have human resources training and they often create different hiring processes even in very similar schools. In addition, principals tend to hire teachers based on their individual interpretation

KIMBREL / DOI: 10.5929/9.2.2 
TEACHER HIRING

and perceptions of the candidate's competency, character, and chemistry (Bourke, 2012), rather than candidates who are a close match for the vision of the school (Mertz, 2010). Unfortunately, there is very little literature specific to education to guide principals through a comprehensive hiring process with multiple steps designed to identify candidates with a high probability of success; however, recent teacher quality research does provide direction regarding the beliefs and behaviors of teachers that are most likely to impact student achievement. In addition, there is clear guidance regarding effective hiring practices available from researchers in the field of management. Hiring teachers with the highest likelihood of success would likely reduce the need for time-intensive and costly remediation, or, in the worst-case scenario, implementation of a teacher non-renewal process. It is also possible that the impact of teachers on student learning may be increased if educational leaders utilize research-based hiring processes.

Given the gap in the literature, inconsistency in practice, and the potential positive impact on student outcome that an effective teacher hiring processes may have, this study was designed to examine the actual hiring processes utilized in schools in order to determine the extent to which research-based practices were utilized and whether principals' perceptions of effective hiring practices correspond with what is known from the current research. Research questions for this study include the following:

RQ1. What elements do principals include in their teacher hiring processes and do those elements reflect best practice as defined by selection science and teacher quality literature?

RQ2. How do principals determine which elements to include in their teacher hiring processes?

RQ3. What teacher characteristics or traits influence the final selection of candidates?

RQ4: How are principals trained to create and implement teacher selection processes?

\section{Literature Review}

\section{Teacher hiring as an element of school improvement}

In response to the growing body of literature on the importance of teacher quality, significant progress has been made to improve both pre-service and in-service training for teachers. Many universities have increased rigor in pre-service teaching preparation programs and state departments of education have increased credentialing requirements (Jacob, 2016). In addition, changes in curriculum alignment, evaluation, and professional development have also increased the quality of in-service teachers (WestEd, 2000). Some researchers, however, have concluded that teacher hiring is an often overlooked, yet essential element of school improvement because of the clear link between competent teachers and high student achievement (Clement, 2009). In fact, most principals agree that hiring qualified and effective teachers is one of their most important roles (Pillsbury, 2005) and that bad hiring decisions are extremely detrimental to both student achievement and school culture (Clement, 2009).

Hiring a teacher who proves to be ineffective and must be dismissed within a few years not only impacts student achievement; but also creates a monetary and emotional drain on a school and its community. In 2006, the National Commission on Teaching and America's Future conducted a study of the cost of teacher turnover in a variety of school districts and found that the costs ranged anywhere from $\$ 10,000$ per teacher to $\$ 26,500$ per teacher (Barnes, Crowe, \& Schaefer, 2007). This financial burden creates a devastating impact on any school budget, but it is especially difficult for a school in a high poverty area with significant teacher turnover. Teacher turnover also causes emotional stress within a school for staff and academic setbacks for students. Ronfeldt, Loeb and Wykoff (2013) found that teacher departure causes overall declines in the morale for teachers, the students of the teachers that leave, and the students of the teachers that stay. Additionally, they reported that student achievement declined during periods of teacher turnover. Kraft, Marinell, and Shen-Wei Yee (2016) similarly found that improvements 
in school leadership, academic expectations, teacher relationships, and school safety are all associated with corresponding reductions in teacher turnover.

Every time a principal hires a new teacher, it is an opportunity to improve the school and outcomes for students (Mertz, 2010) but making accurate predictions about the quality of a teacher during the selection process is very difficult because "traditionally accepted measures of teacher quality such as experience and years of schooling, are only weakly linked with student achievement; they are not reliable proxies for effective teaching" (Hanushek \& Rivkin, 2007, p. 70). In addition, hiring practices in schools have not evolved at the same rate as hiring practices in other industries. A recent nation-wide survey revealed that teacher selection processes often singularly focus on a review of application materials, such as resume and transcripts, rather than performance-based or predictive measures (Konoske-Graf, Partelow, \& Benner, 2016).

Selection science research from the field of management provides direction regarding the elements of a selection process that are most predictive of success during employment. Because no single tool is perfect, and the traditional interview alone is unreliable (Buckley, Norris, \& Wiese, 2000; Deli \& Vera, 2003; Hamdani, Valcea, \& Buckley, 2014; Macan, 2009), the literature advises the development and utilization of a selection system with multiple steps. Moore (2017) identified three essential elements for an effective hiring process: (1) identification of key qualifications and prior experience necessary for success, (2) a structured interview process aligned to identified skills and abilities essential for success on the job and creation of interview questions and acceptable answers in order to assess whether the candidates possess the identified attributes, and ( 3 ) addition of other predictive elements so that decisions are not based solely on paper screening and interviews.

\section{Measures of teacher quality}

The first step of an effective hiring process, as identified by Moore (2017), involves the identification of the key qualifications and prior experience necessary for success at a particular job. Identifying such qualifications for K-12 teachers has been the subject of research over recent years and the body of literature indicates that traditional teacher qualifications have little influence on classroom achievement. Buddin and Zamarro (2009) found no correlation between years of experience, level of education, and teacher licensure test scores on student achievement. They further suggested that researchers and practitioners find other means by which to predict and reward teacher performance. In response to the call for Highly Qualified Teachers within No Child Left Behind, Hanna and Gimbert (2011) examined the effectiveness of teachers who achieved certification through traditional and alternative programs. They found that alternative pathways to teacher certification do not create teachers of lesser quality, but in fact, often successfully bring more individuals from top tier colleges than traditional certification programs. Similarly, Chingos and Peterson (2011) found that neither holding a college major in education nor acquiring a master's degree is correlated with elementary and middle school teaching effectiveness, regardless of the university at which the degree was earned.

Given the lack of connection between teacher background characteristics and student outcomes, principals need to move beyond these types of factors when designing teacher selection processes. Identification of clear and consistent criteria for teacher hiring based on a shared definition of high-quality teaching has also proven to be problematic in practice. Many school hiring teams identify the optimization of student learning as an essential element of teacher success but do not have the training, support, or time to establish the corresponding specific criteria that they seek in candidates (Maynes \& Hatt, 2013). Creating a shared definition of high-quality teachers and specific criteria can also be difficult because it is often a subjective process (Cochran-Smith \& Power, 2010) in which team members do not always agree on what constitutes effectiveness in a particular context (Campbell, Kyriakides, Muijs, \& Robinson, 2003).

KIMBREL / DOI: 10.5929/9.2.2 
Research focused on the beliefs and behaviors of effective teachers offers promise as the basis for a shared definition of a high-quality teacher that is then utilized to drive teacher selection rather than typical background characteristics, such as years of experience and level of education. Schmid (2018) found that teachers who believed that all students could learn and that student learning was a direct reflection of their own teaching practice were likely to have a higher impact on student outcomes. The same study also found that teachers engaged in their own professional learning, including collaboration with colleagues and using student data to drive instruction, was a characteristic of high-impact teachers. This notion of teachers who understand their impact as an indicator of success was also a strong aspect of meta-analyses conducted by Hattie \& Zierer (2018), who describe a set of mind frames that educators should either possess or develop in order to maximize their impact on student learning. The most critical factor for success reported by Hattie \& Zierer was a teacher who sees learning from the perspective of the student and understands how his or her own beliefs and behaviors impacted students.

\section{Structured interviews}

The traditional employment interview is the most commonly used tool for the selection of employees in industries and organizations across the United States (Crosby, 2000) and the field of education is no exception as most principals rely on interviews as their primary source of information regarding a candidate (Cannata et al., 2017). Despite its popularity, the traditional interview is among the most unreliable elements of the selection process in any industry (Moore, 2017) and is particularly problematic in education because it offers a very limited opportunity to accurately assess a teacher's pedagogical skills (Engel, 2013). Studies from as early as 1915 reveal that traditional interviews do not allow for accurate assessments regarding the future success of candidates (Eder, Kacmar, \& Ferrris, 1989) and even the very early researchers found that interviews were predictive of little more than an applicant's appearance, manners, and likability (Buckley, Norris, \& Wiese, 2000). A Meta-analysis of 80 years of research has identified the correlation between interview performance and job performance at only .38 (Schmidt \& Hunter, 1998). This lack of validity and reliability is a result of a combination of factors including interviewer bias and the impact of first impressions, which are often the primary determinants of the successful applicant (Segrest et al., 2006). According to Joyce (2008), some interviewer decisions are made within the first 30 seconds of meeting the candidate and these decisions are often based on appearance, confidence, eye contact, enthusiasm, knowledge of the hiring organization, ability to sell one's self, and clear communication, rather than responses to questions or ability to perform well on the job.

Interviews have long been the most popular method of employee selection and are likely to remain so. The validity and reliability of the interview process can be greatly improved if there is a reduction of bias and inconsistency, which can be accomplished through the addition of elements of structure (Moore, 2017). Although there is not consensus in management literature regarding a common definition of a structured interview, the main themes typically include a set of rules about the creation and delivery of a common set of questions, as well as the assessment of candidates' responses (Lavashina, Hartwell, Morgeson, \& Campion, 2014). Adding structure to an interview significantly increases the correlation of interview performance to job performance, and the correlation determined through meta-analysis has been found to increase to .52 when elements of a structure are added (Schmidt \& Hunter, 1998). Through early meta-analysis, Campion, Palmer, and Campion (1997) established 18 components of structure with rational or empirical links to increased reliability or validity of interviews. Analysis of more recent literature by Lavashina et al. (2014) has reduced this list to six essential elements: (1) job analysis used to create questions, (2) identical questions asked of each candidate, (3) variety of question formats, including situational questions based on past behavior, (4) individual answers rated with a predetermined scale, (5) presence of anchor answers, and (6) presence of trained interviewers. 
Other predictive elements

Moore's (2017) third element of an effective interview process is the addition of other predictive elements so that decisions are not based solely on paper screening and interviews. Although there are many other elements of teacher selection processes that are utilized in practice, there is little evidence to link them to the eventual performance of the individual after he or she has been hired. Elements such as demonstration lessons taught by candidates, problem-solving within a writing sample, and professional task simulations are often referred to as predictive hiring approaches (Maynes \& Hatt, 2013), but in essence, they are actually measures utilized to determine which candidate is the best fit for a specific environment (Pappano, 2011) rather than predictive elements that can be linked to the future success of a teacher.

Similarly, there is not a strong research base for commercially available teacher selection tools, such as screening assessments. In a 2008 study, Metzger \& Wu synthesized 24 studies regarding teacher selection instruments that were widely used at the time and the only tool that had a modest relationship $(r=.28)$ to teaching quality was Gallup's Teacher Perceiver Interview (TPI). Clearly, more research is required to establish other truly predictive measures of teacher performance.

\section{Method}

\section{Participants}

A link to an electronic survey on the Qualtrics platform was emailed to principals in five states in the southern region and five states in the western region of the United States during a two-month period in the spring of 2018. Email addresses were gathered from publically available documents published by state departments of education. In most cases, the e-mail lists were assembled by state departments of education at the beginning of the school year and by spring, there were personnel changes that caused the lists to be somewhat out of date, which resulted in undeliverable e-mails and e-mails delivered to personnel that were no longer principals. In addition, many school district e-mail systems categorized surveys as spam and filtered them so that employees did not receive them. The researcher was also notified of several large districts that would not allow employees to fill out surveys unless prior approval had been granted through the school district's own internal review processes.

In total, 20,367 e-mails were sent to principals in Georgia, Alabama, North Carolina, South Carolina, Arkansas, California, Oregon, Washington, New Mexico, and Utah with 934 returned as undeliverable. Of the 19,433 surveys that were delivered, 1008 surveys were completed, which created a response rate of $5.2 \%$. States were selected for their regional proximity in the south and west and pubic availability of email addresses.

Principals were asked to provide demographic information for their schools. Fifty percent of participants identified that they were located in a rural school, $33 \%$ in a suburban school, and $17 \%$ in an urban setting. Thirty-three percent reported that they had been a principal for $0-3$ years, $27 \%$ for $4-7$ years, $13 \%$ for 8 10 years, and $27 \%$ for 11 years or more. Forty-six percent reported that they were elementary principals, $18 \%$ middle school, $26 \%$ high school, and $9 \%$ identified as principals of a K-8 school. Forty-five percent indicated that their school was located in a county-wide K-12 district, 29\% in a city-wide K-12 district, 13\% in a K-12 unified district serving multiple cities but that does not adhere to county borders, $4 \%$ in a high school only district, and $8 \%$ in an elementary school only district.

\section{Instrumentation}

The survey questions were written based on the research questions of this study, as well as an extensive review of existing research on the topics of teacher quality, teacher selection processes, and best practices 
in employee selection processes. The survey and question construction were guided by Cresswell \& Cresswell (2018). A pilot survey was e-mailed to ten volunteer participants, who were either current or former principals. Revisions to the survey were made based on the feedback and suggestions of those who participated in the pilot survey. Data were self-reported, but bias is limited because the anonymous participants had no stake in the outcome and nothing to gain or lose by reporting any type of data. The survey included 42 multiple choice type questions, which requested information on the demographics of the school and the process used to hire teachers. A total of nine survey questions were directly related to this study.

Two survey questions pertained to the elements of the selection process utilized in the principal's school. The first question in this category asked, "Which elements are regularly included in your teacher selection process?" Answer choices included "research-based screening assessment," "traditional interview with a principal and/or assistant principal," "research-based predictive interview that results in measurable data," "panel interview that includes teachers or other staff members," "panel interview that includes students," "panel interview that includes parents," "interview with board members," "demonstration lesson," "writing sample," "reference checks," "interview with superintendent," and "phone interview." The second question regarding elements of the selection process asked, "What influences the elements that are a part of your teacher selection process?" Respondents were asked to rank the following responses in order of most important to least important: "evidence-based practices from selection science research," "tradition in my school district," "requirements from the district office," "my opinions as a leader about what is important at the time of hiring," "interview processes that I have been a part of in the past," "the number of candidates for the opening," and "training that I have received regarding effective selection processes."

Four questions were included in the survey to determine if principals include elements of predictive, structured interviews in their teacher selection processes. The first question asked, "What portion of the interview questions are developed prior to the first interview?" Answer choices were: "all of the questions," "some of the questions," and "none of the questions." The second question asked, "During the interview, how often are identical questions asked of those being interviewed for the position?" Answer choices were: "always," "about half the time," "sometimes," and "never." Principals also responded to the question, "Are interview questions designed to identify teacher qualities that are known through research to be predictive of high performance?" Answer choices were: "yes," "no," and "not sure." The final question designed to determine the presence of structured interview elements was, "Do interviews result in measurable data?" Answer choices were: "yes," "no," and "not sure."

In order to test if the final selection of teacher candidates were based on qualities known through previous research to be associated with effective teachers, principals were asked, "How important are each of the factors below in the final selection of which applicant is offered a teaching position?" Principals rated "experience," "content knowledge," "certification," "master's degree," "grade point average," "ability to collaborate with colleagues," "ability to build relationships with students," "ability to ensure student growth," "research-based qualities known to be predictive of high teacher performance," and "measurable data from predictive interviews" on a Likert type scale with the options of "extremely important," "very important," "moderately important," "slightly important," and "not at all important."

Finally, two survey questions were designed to elicit an understanding of participants' experience with teacher selection training. The first question was, "What type of training have you received regarding the selection of high-quality teachers?" Answer choices were: "my district provides regular training on research-based selection methods," "I have been trained to administer predictive interviews that generate measurable data," "teacher selection was covered in a graduate or leadership certificate 
TEACHER HIRING

program," "I have attended workshops or conferences about personnel selection," and "none." Finally, principals were asked, "Do you feel that you would benefit from additional training regarding the selection of highly effective teachers?" Answer choices were: "definitely yes," "probably yes," "might or might not," "probably not," and "definitely not."

Survey results were analyzed and reported descriptively. The analysis was performed using Qualtrics and SPSS software to generate the frequency of responses, valid percentages for each of the survey questions, and standard deviations.

\section{Results}

\section{Elements of teacher selection processes}

In order to determine the presence of research-based elements in teacher selection processes, principals were asked to choose all responses that applied to the question, "What elements are regularly included in your teacher selection process?" Table 1 includes the responses for each of the identified elements.

Table 1

Elements included in the teacher selection process

\begin{tabular}{lcc}
\hline & Choice & \\
Element & Count & Percent \\
\hline Research based screening assessment & 75 & $2.93 \%$ \\
Traditional interview with a principal and/or assistant principal & 563 & $21.98 \%$ \\
Research based predictive interview that results in measurable data & 29 & $1.13 \%$ \\
Panel interview that includes teachers or other staff members & 589 & $22.99 \%$ \\
Panel interview that includes students & 31 & $1.21 \%$ \\
Panel interview that includes parents & 53 & $2.07 \%$ \\
Interview with school board member & 23 & $0.90 \%$ \\
Demonstration lesson & 175 & $6.83 \%$ \\
Writing sample & 110 & $4.29 \%$ \\
Reference checks & 648 & $25.29 \%$ \\
Interview with superintendent or asst. superintendent & 106 & $4.14 \%$ \\
Phone interview & 160 & $6.25 \%$ \\
\hline Total & 2562 & $100.00 \%$ \\
\hline
\end{tabular}

The results indicate that principals put a strong emphasis on traditional interviews conducted by an administrator. Over $28 \%$ of the total responses were in the categories of an interview with a principal, assistant principal, or superintendent. Panel interviews with a single candidate and groups of interviewers were also favored by principals. Over a quarter of the total items selected on this question included the phrase "panel interview." Principals placed a high value on reference checks with over a quarter of the total items selected in that category as well. Selection process elements that mention "research" were among the least selected items. "Research-based screening assessment" received only $2.93 \%$ of the total responses and "research-based predictive interview that results in measurable data" received only $1.13 \%$ of the total responses.

In order to determine if research is considered as principals create teacher selection processes, survey participants were asked to rate what influenced their decision to include or exclude certain selection 
TEACHER HIRING

activities. Participants were given seven statements and asked to rate them on a scale of one to seven, with one being most important and seven the least important. Table 2 includes the results of their ratings.

Table 2

Influences of elements included in teacher selection process

\begin{tabular}{lllllllll}
\hline Influence & $\begin{array}{l}\text { Mean } \\
\text { (SD) }\end{array}$ & Rank 1 & Rank 2 & Rank 3 & Rank 4 & Rank 5 & Rank 6 & Rank 7 \\
\hline Evidence based practices & & & & & & & \\
from science and research & 4.17 & 96 & 105 & 75 & 101 & 73 & 93 & 143 \\
& $(2.12)$ & $13.99 \%$ & $15.31 \%$ & $10.93 \%$ & $14.72 \%$ & $10.64 \%$ & $13.56 \%$ & $20.85 \%$ \\
\hline Tradition in my school district & 4.75 & 27 & 79 & 71 & 113 & 114 & 137 & 145 \\
& $(1.80)$ & $3.94 \%$ & $11.52 \%$ & $10.35 \%$ & $16.74 \%$ & $16.62 \%$ & $19.97 \%$ & $21.14 \%$ \\
\hline $\begin{array}{l}\text { Requirements from the } \\
\text { district office }\end{array}$ & 3.40 & 153 & 112 & 120 & 82 & 93 & 80 & 46 \\
& $(1.92)$ & $22.3 \%$ & $16.33 \%$ & $17.49 \%$ & $11.95 \%$ & $13.56 \%$ & $11.66 \%$ & $6.71 \%$ \\
\hline $\begin{array}{l}\text { My opinions as a leader } \\
\text { about what is important }\end{array}$ & 2.49 & 259 & 134 & 127 & 78 & 54 & 23 & 11 \\
at time of hiring & $(1.56)$ & $37.76 \%$ & $19.53 \%$ & $18.51 \%$ & $11.37 \%$ & $7.87 \%$ & $3.35 \%$ & $1.6 \%$ \\
\hline $\begin{array}{l}\text { Interview processes I have } \\
\text { been a part of in the past }\end{array}$ & 3.64 & 64 & 126 & 146 & 127 & 128 & 73 & 22 \\
& $(1.60)$ & $9.33 \%$ & $18.37 \%$ & $21.28 \%$ & $18.51 \%$ & $18.66 \%$ & $10.64 \%$ & $3.21 \%$ \\
\hline $\begin{array}{l}\text { Number of candidates for the } \\
\text { opening }\end{array}$ & 5.19 & 24 & 40 & 56 & 83 & 136 & 156 & 191 \\
\hline $\begin{array}{l}\text { Training I have received } \\
\text { regarding effective practices }\end{array}$ & $(1.68)$ & $3.5 \%$ & $5.83 \%$ & $8.16 \%$ & $12.1 \%$ & $19.83 \%$ & $22.74 \%$ & $27.84 \%$ \\
\hline
\end{tabular}

Principals indicated that "my opinion as a leader based on what is important at the time of hiring" was the most important determinant of the structure of the hiring process. Interestingly, this item also had the lowest variability with a standard deviation of 1.56, which indicates the certainty of the participants regarding this statement. The statement "requirements from the district office" was also ranked as an important consideration for principals. The least important influences for principals were "number of candidates for the opening," and "tradition in my school district."- Principals also indicated that training and evidence-based practices were among the least important considerations. These items also had the highest variability with standard deviations of 1.97 and 2.12 respectively.

\section{Presence of structured interview elements}

Four survey questions were designed to determine if principals utilize components of structured interviews with high predictive power in their teacher selection processes. These questions were asked to both determine levels of use of best practices, as identified by the literature, as well as to verify if the percentage of principals who reported using "research-based predictive interviews that result in measurable data" aligned with the percentage of those who could identify the actual components of structured and predictive interviews.

When principals were asked, "What portion of the interview questions are developed prior to the first interview?" Eighty-one percent of principals answered "all of the questions," $18 \%$ answered "some of the 
TEACHER HIRING

questions," and $0.57 \%$ answered "none of the questions." Principals were also asked, "During the interview, how often are identical questions asked of those being interviewed for the same position?" Eighty-seven percent answered "always," 5\% answered "about half the time," 5\% answered "sometimes,"; and 3\% answered "never." The next question asked, "Are interview questions designed to identify teacher qualities that are known through research to be predictive of high performance?" Seventy percent of principals indicated "yes," $9 \%$ indicated "no," and 21\% replied "not sure." Finally, principals answered the question, "Do interviews result in measurable data?" Forty-three percent of principals indicated "yes," 38\% indicated "no," and 19\% indicated "not sure."

Principals' responses clearly indicated an understanding of the value of a consistent set of questions for each candidate that were prepared prior to the interview. Most principals also believed that the interview questions that they developed were aligned with teacher quality research; however, they were less clear about whether their interviews resulted in measurable data, with an almost even split between yes and no, and almost $20 \%$ who were not sure.

\section{Influences on the final selection of teacher candidates}

In order to determine if principals make the final the selection of teacher candidates based on qualities known through research to be associated with effective teachers, they were asked, "How important are each of the factors below in the final selection of which applicant is offered a teaching position?" The results are shown in Table 3.

The areas rated as most important to principals were "ability to build relationships with students" with a mean score of 1.32, "certification" with a mean score of 1.49, and "ability to collaborate with colleagues" with a mean score of 1.57. Each of these responses also had the lowest variability. The areas of least importance to principals when hiring a teacher were "GPA" with a mean score of 3.95, and "masters' degree" with a mean of 3.81. "Measurable data from predictive interviews" with a mean score of 3.25, "research-based qualities known to be predictive of high teacher performance" with a mean score of 2.65, and "ability to cause student growth" also were rated as unimportant to principals. 
Table 3

Influences of final selection of teacher candidate

\begin{tabular}{|c|c|c|c|c|c|c|}
\hline Influence & $\begin{array}{l}\text { Mean } \\
(\mathrm{SD})\end{array}$ & $\begin{array}{l}\text { Extremely } \\
\text { Important }\end{array}$ & $\begin{array}{c}\text { Very } \\
\text { Important }\end{array}$ & $\begin{array}{l}\text { Moderately } \\
\text { Important }\end{array}$ & $\begin{array}{c}\text { Slightly } \\
\text { Important }\end{array}$ & $\begin{array}{l}\text { Not at all } \\
\text { Important }\end{array}$ \\
\hline \multirow[t]{2}{*}{ Experience } & 2.47 & 139 & 198 & 225 & 82 & 20 \\
\hline & $(1.05)$ & $20.93 \%$ & $29.82 \%$ & $33.89 \%$ & $12.35 \%$ & $3.01 \%$ \\
\hline \multirow[t]{2}{*}{ Content knowledge } & 1.76 & 280 & 281 & 92 & 10 & 2 \\
\hline & $(.77)$ & $42.11 \%$ & $42.26 \%$ & $13.89 \%$ & $1.50 \%$ & $.30 \%$ \\
\hline \multirow[t]{2}{*}{ Certification } & 1.49 & 422 & 175 & 52 & 10 & 4 \\
\hline & (.75) & $63.65 \%$ & $26.40 \%$ & $7.84 \%$ & $1.51 \%$ & $.60 \%$ \\
\hline \multirow[t]{2}{*}{ Masters' degree } & 3.81 & 9 & 39 & 218 & 199 & 198 \\
\hline & (.97) & $1.36 \%$ & $5.88 \%$ & $32.88 \%$ & $30.02 \%$ & $29.86 \%$ \\
\hline \multirow[t]{2}{*}{ Grade point average } & 3.95 & 5 & 32 & 159 & 258 & 207 \\
\hline & (.90) & $.76 \%$ & $4.84 \%$ & $24.05 \%$ & $39.03 \%$ & $31.32 \%$ \\
\hline \multirow{2}{*}{$\begin{array}{l}\text { Ability to collaborate } \\
\text { with colleagues }\end{array}$} & 1.57 & 370 & 239 & 35 & 12 & 8 \\
\hline & (.78) & $55.72 \%$ & $35.99 \%$ & $5.27 \%$ & $1.81 \%$ & $1.20 \%$ \\
\hline \multirow{2}{*}{$\begin{array}{l}\text { Ability to build } \\
\text { relationships with } \\
\text { students }\end{array}$} & 1.32 & 490 & 150 & 21 & 1 & 5 \\
\hline & $(.62)$ & $73.46 \%$ & $22.49 \%$ & $3.15 \%$ & $.15 \%$ & $.75 \%$ \\
\hline \multirow{4}{*}{$\begin{array}{l}\text { Ability to ensure } \\
\text { student growth } \\
\text { Research-based } \\
\text { qualities known to be } \\
\text { predictive of high } \\
\text { teacher performance }\end{array}$} & 1.95 & 241 & 285 & 93 & 26 & 20 \\
\hline & $(.96)$ & $36.24 \%$ & $42.86 \%$ & $13.98 \%$ & $3.91 \%$ & $3.01 \%$ \\
\hline & 2.65 & 153 & 208 & 134 & 50 & 115 \\
\hline & (1.37) & $23.18 \%$ & $31.52 \%$ & $20.30 \%$ & $7.58 \%$ & $17.42 \%$ \\
\hline \multirow{2}{*}{$\begin{array}{l}\text { Measurable data from } \\
\text { predictive interviews }\end{array}$} & 3.25 & 73 & 156 & 150 & 84 & 189 \\
\hline & (1.38) & $11.20 \%$ & $23.93 \%$ & $23.01 \%$ & $12.88 \%$ & $28.99 \%$ \\
\hline
\end{tabular}

\section{Principal training}

To determine the level of teacher selection training that principals possess, survey participants were asked to check all responses that applied to the question, "What kind of training have you received regarding the selection of high-quality teachers?" The response "my district provides regular training on researchbased selection processes" was selected by $12.28 \%$ of participants, $13.74 \%$ selected "I have been trained to administer predictive interviews that generate measurable data," $27.47 \%$ selected "teacher selection was covered in a graduate or leadership certificate program," $29.66 \%$ selected that they have attended workshops or conferences about personnel selection, and $16.86 \%$ indicated that they had not received training. When asked, "Do you feel that you would benefit from additional training regarding the selection of highly effective teachers," 35.54\% answered "definitely yes," 39.46 answered "probably yes," $16.72 \%$ answered "might or might not," 7.38 answered "probably not," and 0.09\% answered "definitely not."

Results indicated that principals are most likely to have received teacher selection training during a graduate course or from a workshop rather than training provided by their district office and very few had 
received specific training to utilize predictive, structured interviews. Given this low level of training, it was not surprising that only about $8 \%$ of principals felt that they would not benefit from additional training.

\section{Discussion}

\section{Elements of teacher selection processes}

Principals indicated that traditional employment interviews were the most utilized element of teacher selection processes with over $28 \%$ of responses that included a scenario with one candidate and one interviewer. Interviews with one candidate and several interviewers were also a heavily used strategy with over $25 \%$ of responses that included panel interviews. These findings align with recent literature, which identifies interviews as the most relied upon source of information for principals as they consider teaching candidates (Cannata et al., 2017). This finding is not surprising, but problematic given that the traditional interview is among the most unreliable elements of selection processes in any industry, including education (Moore, 2017; Engel, 2013). Conversely, selection process elements that mention research were among the least selected items. These results indicate that principals are either not aware of personnel selection research or choose not to implement research-based elements that would significantly increase the validity, reliability, and predictability of the selection process (Lavashina et al., 2014; Moore, 2017; Schmidt \& Hunter, 1998).

Principals were also asked to identify how decisions are made regarding which elements to include or exclude in their teacher selection processes. In a forced-choice ranking where 1 was most important and 7 least important, principals indicated that "my opinion as a leader based on what is important at the time of hiring" was the most important determinant of the structure of the hiring process with a mean score of 2.49. This finding suggests that principals do not have consistent processes and that changes occur based on the principals' perception of the hiring climate or conditions. "Requirements from the district office" was also ranked as an important consideration for principals, although, it had a much higher mean score of 3.40. Following requirements from the district office is an interesting contradiction to the most popular answer of doing whatever the principal feels is right at the moment. "Training I have received regarding effective practices" and "evidence-based practices from science and research" were among the least important considerations for principals and had the highest variability. These results corroborate other results from this study that principals are much more likely to use traditional interviews than research-based predictive screening or interview methods.

\section{Presence of structured interview elements}

Principals responded to several questions in order to determine if they utilized components of structured interviews with high predictive power in their teacher selection processes, even if they did not necessarily identify their entire process as "research-based." Through meta-analysis, Lavashina et al. (2014) identified six components of structure for interviews with rational and empirical links to increased reliability and validity: (1) job analysis used to create questions, (2) identical questions asked of each candidate, (3) variety of question formats including situational questions based on past behavior, (4) individual answers rated with a predetermined scale, (5) presence of anchor answers, and (6) trained interviewers.

The survey results clearly indicated that principals were utilizing some of the most basic elements of structure but not those with more complexity that would likely require training to implement. Almost $82 \%$ of principals indicated that their interview questions were developed prior to the interview and just over $87 \%$ of principals indicated that the same set of questions were asked to all candidates. Results were less consistent when principals were asked if interview questions were specifically designed to identify teacher qualities that are known through research to be predictive of high performance. Seventy percent of principals indicated that they believed their questions were designed in this manner and $21 \%$ were not 
sure. Finally, only $43 \%$ of principals reported the use of interviews that result in measurable data. Thirtyseven percent of principals indicated that their interviews do not result in measurable data and $19 \%$ were unsure. It is likely that if a principal is unsure if the data is measurable, that it is not.

\section{Influences on final selection of teacher candidates}

To determine if principals made job offers to teacher candidates based on qualities known through research to be associated with effective teaching, principals were asked to rate a variety of factors. The qualities with the highest ratings were the "ability of a teacher to build a relationship with students" and "ability to collaborate with colleagues." Both themes are strongly supported in the teacher quality literature as being factors closely related to student achievement (Hattie, 2011; Hattie \& Zierer, 2018; DuFour, DuFour, \& Eaker, 2008). Principals also rated "certification" as an important element in their decision-making process. Teacher certification is a flat credential that is earned one time and then renewed and has not been proven to substantially impact the effectiveness of the teacher (Hanna \& Gimbert, 2011), but it is understandable that principals valued a certificate due to legal and policy requirements of their states and districts. Similar to the other findings of this research, measurable data from predictive interviews and research-based qualities known to be predictive of high teacher performance were relatively unimportant to principals, which again indicates a lack of use, and perhaps lack of understanding, of research-based hiring methods. The ability to cause student growth, which is the primary purpose of a school, was also identified as a consideration of relative unimportance to principals.

\section{Principal training}

Results of this study indicate that principals are most likely to have received training in teacher selection processes through a workshop or conference or in a graduate course, rather than through training offered by their district. This is an interesting finding given that principals also indicated that they are very likely to structure their teacher selection processes based on requirements from the district. Training delivered in the workshop format is likely to be a one-time experience without follow up coaching and training in a graduate program is also likely to be minimal and, in some cases, many years in the past. It was alarming that almost $17 \%$ of principals indicated that they had never received any training and $92 \%$ of principals indicated that they could benefit from more training. This finding indicates that principals recognized the inadequacy of their training in effective teacher selection methods.

\section{Conclusions}

The link between an effective teacher and positive student outcomes has been suspected for decades, but recent research has confirmed that students who receive instruction from a high-quality teacher are far more likely to experience success (Darling-Hammond, 2000; Hattie, 2009; Marzano, 2003). Many factors have been shown to have some impact on student achievement, but none is more powerful than the quality of instruction from the teacher; consequently, hiring effective teachers is of the utmost importance and perhaps one of the most impactful roles of the school principal. The responsibility of hiring teachers almost always falls to school principals, and their busy schedules and last-minute hiring needs often result in rushed, information poor hiring decisions where candidates feel that they have very little meaningful interaction with school staff (Liu \& Johnson, 2006). Despite a large amount of recent literature regarding the beliefs and behaviors of effective teachers, this study found that principals tend to rely on their own opinions rather than research when making decisions about the structure of the hiring process and the qualities of the teacher whom they will hire.

Selection science literature from the field of management is abundant and can provide direction for educators regarding the elements and structure of an employee selection system that will reliably identify the applicants who have the greatest likelihood of success while employed. This research can be adapted 
and applied to the teacher hiring process in order to improve outcomes. Because no singular tool is perfect, and the traditional interview alone is unreliable (Buckley, Norris, \& Wiese, 2000; Deli \& Vera, 2003; Hamdani, Valcea, \& Buckley, 2014; Macan, 2009) a selection system with multiple steps should be developed and utilized.

This research found that principals rely upon traditional interviews either with an individual administrator or panel of interviewers as the most likely method to gain information in order to hire teachers. Unfortunately, reliance on a traditional interview has long been known to be problematic because of their lack of predictive power, validity, and reliability (Seagrest Purkiss, Perrewe, Gillespie, Mayes, \& Ferris, 2006). In addition to the problems caused by the widespread use of traditional interviews, this study found that many principals do not have consistent teacher selection processes and are likely to change the elements they include based on their opinion about what is important at the time. This variability further erodes the likelihood that the teachers with the greatest likelihood of success will be hired.

This research also suggests that principals do not utilize research-based teacher selection processes because they are unfamiliar with them or have not been trained to create or implement them. Most principals report very little training on any type of selection process and that the only information they have has been gained from conferences and graduate courses rather than ongoing training in their districts. The lack of training is confounded by the lack of wide-spread effective teacher hiring models by schools and districts in the United States.

The need for training designed to teach principals to more effectively select teachers is clear from the perspective of both best practice and the principals themselves. Only $8 \%$ of principals in this study indicated that did not feel that they would benefit from further training. The results of this study also reveal that there is a strong foundation from which to build for this training. Most principals already use the basic elements of structured interviews, such as a consistent set of questions based on job descriptions that are developed ahead of the interviews so training can add to this skill set.

\section{Implications}

The following questions can be considered for future research:

- Teaching is a complex endeavor and requires different skills and competencies than other professions. Given this level of complexity and the unique nature of teaching, which of the six elements of the interview structure as identified by Lavashina et al. (2014) have the most impact on the validity and reliability of teacher selection?

- Given current and predicted teacher shortages in critical areas, does the use of structured interviews and other predictive elements impact a teacher's perception of a school? Does the use of structured interviews and predictive screeners impact the desirability of a school or the acceptance rate of job offers?

- What screening tools can be developed and utilized to accurately determine the beliefs and behaviors of teacher candidates in order to make the screening process more effective than simply weeding out candidates without minimum qualifications?

- What barriers and concerns exist for principals that prevent the use of research-based hiring practices?

Despite the many questions that remain for researchers, there are immediate and practical implications for practitioners. Ensuring that every student learns at high levels is a complex task that requires skillful teachers and a change to the status quo in most schools; therefore, hiring the best possible teachers is an 
essential component of school reform. One promising approach to reducing hiring bias and increasing the probability of hiring teachers with the ability to significantly increase student learning is to screen candidates for only the qualities that research has shown to be predictive of success and to add elements of structure that will increase the predictive nature of interviews. Practitioners can engage in action-based research in their schools and districts to determine if changing the hiring process by adding researchbased elements increases their ability to select teachers with a high impact on student growth and to meet the demand for high-quality teachers in every classroom. Another implication for practitioners is the clear need for training designed to teach principals to more effectively select teachers.

\section{References}

Buddin, R., \& Zamarro, G. (2009). Teacher qualifications and student achievement in urban elementary schools. Santa Monica, CA: Rand Corporation. Retrieved from https://www.rand.org/pubs/reprints/RP1410.html.

Ballard, K., \& Bates, A. (2008). Making a connection between student achievement, teacher accountability, and quality classroom instruction. The Qualitative Report, 13(4), 560-580. Retrieved from https://nsuworks.nova.edu/tqr/vol13/iss4/3

Barnes, G., Crowe, E., \& Schaefer, B. (2007). The cost of teacher turnover in five school districts: A pilot study. Arlington, VA: National Commission on Teaching and America's Future.

Bourke, K. B. (2012). Public secondary school principals' perspectives on teacher hiring: What matters most? (Doctoral dissertation). Retrieved from ProQuest, LLC. (Accession No. ED551731)

Buckley, R. M., Norris, A.C., \& Wiese, D. S. (2000). A brief history of the selection interview: May the next 100 years be more fruitful. Journal of Management History, 6(3), 113-126.

Campbell R. J., Kyriakides, L., Muijs, R. D., \& Robinson, W. (2003). Differential teacher effectiveness: Towards a model of research and teacher appraisal. Oxford Review of Education, 29, 347-362.

Campion, M. A., Palmer, D. K., \& Campion, J. E. (1997). A review of structure in the selection interview. Personnel Psychology, 50(3), 655-702.

Cannata, M., Rubin, M., Goldring, E., Grissom, J. A., Neumerski, C.M., Drake, T. A., \& Schuermann, P. (2017). Using teacher effectiveness data for information-rich hiring. Educational Administration Quarterly, 53(2), 180-222.

Chingos, M. M., \& Peterson, P. E. (2011). It's easier to pick a good teacher than to train one: Familiar and new results on the correlates of teacher effectiveness. Economics of Education Review, 30(3), 449465.

Clement, M. C. (2009). Hiring highly qualified teachers begins with quality interviews. Kappan, 9(2), 2224.

Cochran-Smith, M., \& Power, C. (2010). New directions for teacher preparation. Educational Leadership, 67(8), 6-13.

Cresswell, J. W. \& Cresswell, J. D. (2018). Research design: Qualitative, quantitative, and mixed method approaches ( $5^{\text {th }}$ ed.). Thousand Oaks, CA: Sage Publications.

Darling-Hammond, L. (2000). Teacher quality and student achievement: A review of state policy evidence. Education Policy Analysis Archives, 8(1). 
TEACHER HIRING

Deli, D. A., \& Vera, E. M. (2003). Psychological and contextual influences on the teacher selection interview: A model for future research. Journal of Personnel Evaluation in Education, 17(2), 137218.

DuFour, R., DuFour, R., \& Eaker, R. (2008). Professional learning communities at work: New insights for improving schools. Bloomington, IN: Solution Tree Press.

Eder, R. W., Kacmar, K. M., \& Ferris, G. R. (1989). Employment interview research: History and synthesis. In Eder, R. W. and Ferris, G. R. (Eds.) The employment interview: Theory, research, and practice, (pp. 17-31). London: Sage.

Engel, M. (2013). Problematic preferences? A mixed method examination of what principals' preference for teacher characteristics in Chicago. Educational Administration Quarterly, 49, 52-91.

Hanna, P., \& Gimbert, B. (2011). Falling flat: Certification as an insufficient indicator of teacher quality. Journal of the National Association for Alternative Certification, 6(2), 31-52.

Hamdani, M. R., Valcea, S., \& Buckly, R. M. (2014). The relentless pursuit of construct validity in the design of employment interviews. Human Resource Management Review, 24(2), 160-176.

Hanushek, E. A. \& Rivkin, S. G. (2007). Pay, working conditions and teacher quality. The Future of Children, 17(1), 69-86.

Hattie, J. (2009). Visible learning: A synthesis of over 800 meta-analyses related to achievement. New York, NY: Routledge.

Hattie, J., \& Zierer, K. (2018). 10 Mind frames for visible learning: Teaching for success. New York, NY: Routledge.

Jacob, B. (2016). The power of teacher selection to improve education. (Report No. 12) Evidence Speaks Reports Volume 1, Washington, DC: Economics Studies at Brookings.

Joyce, M. P. (2008). Interviewing techniques used in selected organizations today. Business Communication Quarterly, 71(3), 376-380.

Konoske-Graf, A., Partelow, L., Benner, M. (2016, December 22). To attract great teachers, school districts must improve their human capital systems. Retrieved from https://www.americanprogress.org/issues/education-k-12/reports/2016/12/22/295574/toattract-great-teachers-school-districts-must-improve-their-human-capital-systems/

Kraft, M. A., Marinell, W.H., \& Shen-Wei Yee, D. (2016). School organizational contexts, teacher turnover, and student achievement. American Educational Research Journal, 53 (5), 1411-1449.

Lavashina, J., Hartwell, C. J., Morgeson, F. P., \& Campion, M. A. (2014). The structured employment interview: Narrative and quantitative review of the research literature. Personnel Psychology, (67)1, 241-293.

Liu, E. \& Johnson, S. M. (2006). New teachers' experiences of hiring: Late, rushed and information poor. Educational Administration Quarterly, 42(3), 324-360.

Macan, T. (2009). The employment interview: A review of current studies and directions for future research. Human Resource Management Review, 19(3), 203-218.

Maynes, N., \& Hatt, B. E. (2011). Grounding program change in students' learning: A model for the conceptual shift in thinking that will support valuable program change in response to faculty of education reviews. In T. Falkenberg \& H. Smits (Eds.), The question of evidence in research in 
teacher education in the context of teacher education program review in Canada (2 vols.). Winnipeg: University of Manitoba, Faculty of Education.

Marzano, R. (2003). What works in schools: Translating research into action. Alexandria, VA: ASCD.

Mertz, N. (2010). Teacher selection and school leader effects. Journal of School Leadership, 20(2), 184207.

Metzger, S. A., \& Wu, M. J. (2008). Commercial teacher selection instruments: The validity of selecting teachers through beliefs, attitudes, and values. Review of Educational Research, 60(4), 921-940.

Moore, D. A. (2017). How to improve the accuracy and reduce the cost of personnel selection. California Management Review, (60)1, 8-17.

Pappano, L. (2011). Using research to predict great teachers. Harvard Education Letter, 27(3).

Pillsbury, P. (2005). Only the best: hiring outstanding teachers. Leadership, 35(2), 36-38.

Ronfeldt, M., Loeb, S., \& Wyckoff, J. (2013). How teacher turnover harms student achievement. American Education Research Journal, 50(1), 4- 36.

Seagrest Purkiss, S. L., Perrewe, P. L., Gillespie, T. L., Mayes, B. T., \& Ferris, G. R. (2006). Implicit sources of bias in employment interview judgments and decisions. Organizational Behavior and Human Decision Processes, 101(2), 152-167.

Schmidt, F. L. \& Hunter, J. E. (1998). The validity and unity of selection and methods in personnel psychology: Practical and theoretical implications of 85 years of research findings. Psychological Bulletin, 124 (2), 262-274.

Stronge, J., Ward, T., Tucker, P., \& Hindman, J. (2008). What is the relationship between teacher quality and student achievement? An exploratory study. Journal of Personnel Evaluation in Education, 20(3):165-184

Teachers matter: Understanding teachers' impact on student achievement. (2012). Santa Monica, CA: RAND Corporation. Retrieved from https://www.rand.org/pubs/corporate_pubs/CP693z1-201209.html

Troutman, L. D. (2012). The impact of principal leadership on school culture and student achievement. (Doctoral dissertation). Retrieved from ProQuest, LLC (Accession No. ED551410)

WestED. (2000). Ensuring teacher quality: A continuum of teacher preparation and development policy brief. San Francisco, CA: WestED.

\section{About the Author}

Laurie Kimbrel (lkimbrel@westga.edu) is an Assistant Professor in the Department of Leadership, Research, and School Improvement at the University of West Georgia in Carrollton, GA. Prior to working in higher education, she had a 27-year career as a teacher and leader in K-12 public schools in Illinois, California, and Georgia, including seven years as a superintendent. 